\title{
POR UM JORNALISMO HUMANIZADO: O SILÊNCIO SOBRE AS MORTES DAS MULHERES E DOS HOMENS “INFAMES" EM ZERO HORA'
}

\author{
Arthur Walber VIANA \\ Mestrando do Programa de Pós-Graduação em Comunicação e Informação da UFRGS \\ arthurwalber@hotmail.com \\ Valdir Jose MORIGI
}

Doutor em Sociologia e Professor Titular do Departamento de Ciências da Informação e do Programa de PósGraduação em Comunicação e Informação da UFRGS, Pós-doutorando em Memória Social (PPGMS/UNIRIO)

valdir.morigi@gmail.com

\begin{abstract}
Resumo
$\mathrm{O}$ artigo analisa como as mortes de pessoas em situação de rua são relatadas pelo jornalismo tradicional. Toma como referencial teórico os Estudos Culturais, que consideram os acontecimentos inseridos em seus contextos, além de perceberem as imbricações das relações de poder na construção dos discursos jornalísticos sobre a realidade social. O método utilizado é a Análise de Discurso na perspectiva de Orlandi (1992; 1999), com foco nas palavras e suas ausências. O recorte do estudo são notícias publicadas no site do jornal Zero Hora, de Porto Alegre (RS), durante o primeiro semestre de 2017 que relatam casos de violência contra moradoras e moradores de rua. Conclui-se que as relações entre o dito e o não-dito no discurso do jornal favorece o silenciamento do Outro. Isso mostra a ausência - e a necessidade - de um discurso jornalístico humanizado ao tratar de sujeitos que vivem em situação de exclusão social.
\end{abstract}

Palavras-chave: Teorias do Jornalismo. Moradores de rua. Zero Hora.

\section{FOR A HUMANIZED JOURNALISM: SILENCE ON THE DEATH OF “INFAMOUS” WOMEN AND MEN IN ZERO HORA}

\begin{abstract}
The article analyzes how the deaths of homeless people are reported by traditional journalism. It takes as a theoretical reference the Cultural Studies, which consider the events inserted in their contexts, besides perceiving the tangles of relations of power in the construction of journalistic discourses on the social reality. The method used is Discourse Analysis from Orlandi's perspective (1992, 1999), focusing on words and their absences. The object of the study are news published on the website of the newspaper Zero Hora, from Porto Alegre (RS), during the first half of 2017 that report cases of violence against homeless people. We conclude that the relations between the said and the unsaid in the newspaper discourse favors the silencing of the Other. This shows the absence and the necessity - of a humanized journalistic discourse when dealing with subjects living in situations of social exclusion.
\end{abstract}

Keyword: Theories of Journalism. Homeless people. Zero Hora.

\footnotetext{
1 Trabalho originalmente apresentado no GP Teorias do Jornalismo do XVII Encontro dos Grupos de Pesquisa em Comunicação, evento componente do $40^{\circ}$ Congresso Brasileiro de Ciências da Comunicação. Com atualizações.
}

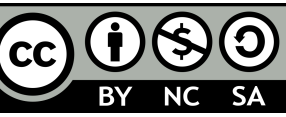




\section{INTRODUÇÃO}

A única certeza da vida, prescreve o dito popular, contudo tanto quanto certa a morte é também imprevisível, a ponto de mesmo quando iminente, seja por motivo de doença grave seja pelo demasiado avanço da idade, ser ainda impossível prevê-la com exatidão: a morte nos surpreende sempre, devastadora. Por representar tão abrupto rompimento da ordem da vida cotidiana, ruptura radical e total, constitui-se, a morte, como digna do noticiário, tendo em vista os critérios de noticiabilidade do jornalismo: “A ruptura da 'normalidade' consegue um lugar de referência do mundo das notícias" (TRAQUINA, 2013, p.92). Não por acaso, já nos anos 1700 publicavam-se obituários, sintetizando o interesse jornalístico nesses acontecimentos (o The Gentleman's Magazine, de Londres, publicava uma seção de obituário já em $1731^{2}$ ).

Entretanto, fossem noticiadas todas as mortes, não restariam páginas ou tempo de transmissão aos assuntos da política, da economia, da cultura, do esporte: não haveria espaço aos assuntos dos vivos. Em dezesseis anos, entre 1995 e 2011, 903 milhões de pessoas morreram no mundo, o que representa uma média de 56,5 milhões de mortes por ano (mais de 150 mil casos diários) ${ }^{3}$. Segundo a ONU, 16 mil crianças morriam diariamente em $2015^{4}$. Não sendo possível noticiar todas, portanto, qual morte tem valor ao jornalismo? A quem é reservado o espaço do luto público promovido pelos veículos de comunicação da indústria cultural?

Estas são indagações iniciais e, na tentativa de respondê-las, estudaremos os valoresnotícia e os critérios de noticiabilidade do jornalismo, a fim de entender quais fatores fazem um acontecimento se tornar notícia em detrimento de outros. Para além da abordagem da notícia em si, adotaremos as perspectivas de Hall et al. (1978), que enxergam a construção da notícia como parte de um complexo processo de seleção e classificação de acontecimentos “[...] de acordo com um conjunto de categorias socialmente construído" (HALL, et al., 1978, p.53, tradução nossa). Nosso olhar se voltará, principalmente, ao entorno do fazer jornalístico, às

\footnotetext{
${ }^{2}$ Vieira (2014) faz um interessante levantamento sobre as origens do obituário e seus potenciais narrativos. Disponível em: http://www.teses.usp.br/teses/disponiveis/100/100135/tde-21012015-163251/pt-br.php. Acesso em: 21/06/2017.

${ }^{3}$ Pesquisa do Population Reference Bureau. Disponível em: http://www.prb.org/Publications/Articles/2002/HowManyPeopleHaveEverLivedonEarth.aspx. Acesso em: 20/06/2017.

${ }^{4}$ Disponível em: https://nacoesunidas.org/onu-16-mil-criancas-morrem-diariamente-revela-novo-relatorio-sobremortalidade-infantil1/. Acesso em: 21/06/2017.
} 
forças que o moldam de fora para dentro (sem ignorar, frise-se, que o movimento de forças irradia também no sentido inverso).

O objeto do estudo são matérias sobre casos de morte de moradoras e moradores de rua em Porto Alegre ocorridos no primeiro semestre de 2017 publicadas no jornal Zero Hora, maior circulação do Rio Grande do Sul ${ }^{5}$. Verificaremos por que tais casos - que envolvem violência brutal - não tiveram maior repercussão nos veículos do jornalismo tradicional. Os relatos foram estudados à luz da Análise do Discurso (ORLANDI, 1992; 1999), enfatizando como o dito e o não-dito no texto do jornal favorecem o silenciamento do discurso do Outro. Além disso, consideramos os mapas de significação socialmente compartilhados, conforme apontado por Hall et al. (1978), que surgem a partir do discurso de definidores primários.

Queremos saber, afinal, como são tratadas pelo jornalismo tradicional as tragédias do Outro - os pobres e vagabundos, os consumidores falhos (BAUMAN, 1998)? Que espaço o jornal Zero Hora dá aos casos de violência e mortes de moradoras e moradores de rua? A elas e a eles é reservado algum direito à lembrança e registro ou suas existências, mesmo ao fim, são desumanizadas e sentenciadas ao esquecimento?

\section{CRITÉRIOS DE NOTICIABILIDADE E VALORES-NOTÍCIA NO JORNALISMO}

Há três níveis no jornalismo que auxiliam na escolha dos critérios de noticiabilidade, e é importante, de início, ressaltá-los: o jornalista, a empresa e a sociedade (ou o fato, as condições de produção e a ideologia). Por este trajeto poderemos compreender como a morte - e quais mortes - tornam-se sedutoras para os publicadores de notícias - lembrando ser a morte um "atrativo" para o jornalismo (conforme Traquina [2013, p.76], “[o]nde há morte, há jornalistas"). O autor coloca a morte como um valor-notícia fundamental do jornalismo ao afirmar que "[...] todos nós seremos notícia pelo menos uma vez na vida - no dia seguinte à morte, ou nas páginas interiores ou com destaque na primeira página” (TRAQUINA, 2013, p.77).

Embora reconheçamos a morte como um dos valores-notícia a que recorrem jornalistas ao prospectarem e selecionarem os "acontecimentos publicáveis", questionamos tamanha convicção de que toda a morte tem valor ao campo ${ }^{6}$ (o próprio Traquina (2013) fará esta

\footnotetext{
${ }^{5}$ Segundo a Associação Nacional de Jornais (ANJ), dados relativos a 2015 (os mais recentes até a data deste artigo). Disponível em: http://www.anj.org.br/maiores-jornais-do-brasil/. Acesso em: 26/06/2017.

${ }^{6}$ Poderíamos também questionar que, se nos tornamos notícia no dia seguinte à morte, não seremos, então, conteúdo de jornais em vida, como parece sugerir Traquina (2013).
} 
relativização adiante em seu texto, ressaltando a inter-relação entre valores-notícia). Ao refletirmos, a partir daí, sobre quais mortes interessam mais ao jornalismo, identificamos alguns critérios que parecem ser resistentes ao passar do tempo:: Tobias Peucer afirmava já em 1690 que as mortes dignas de recordação e conhecimento eram dos príncipes e dos varões ilustres (PEUCER, 2004, p.21) ${ }^{7}$. A morte por si só, então, não é um critério suficiente para que se efetive como produto jornalístico: ela dependerá fundamentalmente de outros fatores, como quem é o morto - se é um príncipe ou um plebeu, um varão ilustre ou um infame qualquer -, como ocorreu a morte ou quantas pessoas foram afetadas pela ocorrência. É esta uma primeira explicação: os valores-notícia se inter-relacionam, e quantos mais um acontecimento contemplar maior a probabilidade de ganhar os noticiários; eles operam em conjunto, como uma estrutura (HALL et al., 1978).

No entanto, as definições de quais seriam esses valores-notícia são variadas e inconclusivas $^{8}$ : não são regras escritas e, também, não há indicação de quais critérios predominariam frente a outros - ainda assim, não se contesta sua existência, que é palpável:

Apesar de não estarem escritos em lugar algum, nem transmitidos ou codificados formalmente, os valores-notícia parecem ser amplamente compartilhados entre os diferentes veículos de comunicação [...] e formam um elemento central na socialização profissional, na prática e na ideologia de jornalistas (HALL et al., 1978, p.54, tradução nossa).

Nesse ponto, cabe que se faça uma importante distinção entre valor-notícia e critérios de noticiabilidade ${ }^{9}$, reforçada por Silva (2005): valores-notícia são as características do fato em si; são um critério de noticiabilidade. Estes formam um grupo mais amplo, que envolve desde o formato do produto jornalístico, a disposição da força de trabalho e a linha editorial do veículo até o custo da produção e o público-alvo. De maneira mais abrangente, consideramos que os critérios de noticiabilidade do jornalismo estão subordinados a um mapa de significados socialmente compartilhado (HALL et al., 1978), intrinsecamente conectado às ideologias predominantes na sociedade. Os critérios de noticiabilidade se apresentam, portanto, nestes três eixos: 1) o do fato em si e de sua valoração pelo jornalista; 2) o das rotinas de produção, onde há influência decisiva da limitação de tempo, das condições laborais e de constrangimentos organizacionais diversos ${ }^{10}$; e 3) a ideologia proeminente na sociedade, que agirá sobre os outros

\footnotetext{
${ }^{7} \mathrm{O}$ trabalho de Tobias Peucer, de 1690, é tido como a primeira tese acadêmica a respeito do jornalismo.

${ }^{8}$ Silva (2005) faz um levantamento dos valores-notícia a partir de autores de referência e monta um quadro com 12 "macro-valores", aos quais se subordinam outros 51 "micro-valores" - a morte entre estes.

${ }^{9}$ Traquina (2013) faz distinção semelhante entre os valores-notícia substantivos (relativos ao fato em si) e os valores-notícia contextuais (que fazem referência a questões extrínsecas ao fato).

${ }^{10}$ Entre estes constrangimentos estão a autoridade institucional; os sentimentos de obrigação e estima em relação aos superiores; e, entre outros, aspirações de mobilidade. Para aprofundamento, ver "O Estudo do Jornalismo no
} 
eixos, moldando-os, e, da mesma forma, afetará também a decodificação das notícias por parte dos consumidores, reforçando um discurso que se retroalimenta. Silva (2005) ${ }^{11}$ destaca que os eixos definidores do que se tornará notícia não funcionam isoladamente - embora devamos ressaltar a subordinação de um a outro.

\subsection{Os mapas de significação socialmente compartilhados: a ideologia que constrói a "verdade"}

Conforme Berger e Luckmann (2003), a realidade é socialmente construída; isso nos leva a questionar a existência de uma verdade pura que pode (e deve) ser desvendada por jornalistas para mais tarde ser apresentada a seus públicos. O discurso veiculado no jornalismo é um entre vários possíveis. No entanto, dado seu estatuto privilegiado dentro da cultura (BIRD; DARNDENNE, 1999), importa que compreendamos que discurso é esse, amplificado a todos os estratos da sociedade: "A mídia representa a primeira e frequentemente única fonte de informação sobre muitos eventos e tópicos importantes" (HALL et al., 1978, p.56, tradução nossa).

Ser a primeira ou mesmo a única fonte de informação, contudo, não significa que jornalistas ou as empresas onde atuam possam definir e manipular livremente as informações da vida social. Muitas vezes, oprimidos por limitações de tempo e condições laborais adversas $^{12}$, jornalistas recorrem a mapas de atuação que simplificam suas práticas e permitem que vençam a hora de fechamento (TRAQUINA, 2004): entram aí a construção do relato de acordo com a pirâmide invertida ${ }^{13}$, os critérios de objetividade e a procura por fontes já legitimadas e preparadas para lidar com a mídia - são estas, aliás, que Hall et al. (1978) denominam definidores primários, porta-vozes de discursos oficiais e institucionalizados que já ostentam posição privilegiada no meio social e são constantemente abordados pelo jornalismo para que publicizem suas visões sobre os acontecimentos do mundo.

século XX”, de Nelson Traquina (2004), no capítulo dedicado à Teoria Organizacional do sociólogo Warren Breed.

${ }^{11}$ Silva (2005) subdivide os critérios de noticiabilidade entre os momentos de seleção (onde se aplicariam os valores-notícia); a hierarquização e a produção (dos fatos tidos por "noticiáveis"); e, em terceiro, "[a] visão dos fatos, a partir de fundamentos éticos, filosóficos e epistemológicos do jornalismo, compreendendo conceitos de verdade, objetividade, interesse público, imparcialidade que orientam inclusive as ações e intenções das instâncias ou eixos anteriores" (SILVA, 2005, p.96).

${ }^{12}$ Fonseca (2008, p.246) chama atenção para o caso de Zero Hora, onde as jornadas de trabalho podem se estender por dez ou 12 horas, "[...] o que provocaria muitas reclamações trabalhistas".

${ }^{13}$ Responder as perguntas: o quê, quem, quando, onde, como, por quê - feramenta eficaz para o jornalista, mas que "encoraja uma leitura parcial" (BIRD; DARNDENNE, 1999). 
Comentando o baixo índice de transformação discursiva da fala destas fontes, o que significa que seus pontos de vista são menos mediados e mais transmitidos, Ponte (2004, p.65) percebe o jornalismo como “[...] 'porta-voz' de outras autoridades, num tom oficioso e vertical, mas também inquestionado no estatuto de regulador do que é digno de ser notícia”. Promovese, com isso, a unilateralidade da informação (MEDINA, 2008), onde o espaço de fala da notícia, e em decorrência o tom do que é noticiado, é ocupado por quem já está em um local de privilégio no debate público.

Ainda que o processo de feitura da notícia não possa ser reduzido a uma simples reprodução do discurso dos poderosos, ao colocar um ponto de vista na posição de definidor primário, todo o espaço de contestação a essa realidade construída primeiro será sempre em relação a ela - ou seja, será sempre um contra-argumento que precisa "ser" por oposição antes de se afirmar o que quer que seja, pense ou deseje ser de fato. "O efeito final ajuda [...] a fechar o círculo pelo qual as definições dos poderosos se tornam parte da realidade social dada como certa, a partir da tradução do desconhecido para o mundo familiar" (HALL et al., 1978, p.62, tradução e grifos nossos).

Há que se observar que em sociedades fundadas em desigualdades (econômica, racial, de gênero), diferentes mapas de significados emergirão, tão diversos quanto os grupos sociais que os constroem. A relação de forças exercidas nos processos sociais, contudo, determinará um mapa como "consensual": "Essa visão consensual da sociedade é particularmente forte nas sociedades modernas, democráticas, organizadas e capitalistas; e a mídia está entre as instituições cujas práticas são mais ampla e consistentemente baseadas na suposição de um ‘consenso nacional'” (HALL et al., 1978, p.55, tradução nossa). Dessa forma, à noção de um mapa de significados socialmente compartilhado que orienta os atores sociais nas suas práticas da vida cotidiana, inclusive na produção e no consumo de notícias, deve se acrescentar que, na definição desse mapa, há disputas e descontinuidades.

Os próprios profissionais que constroem as notícias, frise-se, e some-se aí também pesquisadoras e pesquisadores e seus discursos científicos, são influenciados (e influenciam) pelos mesmos códigos culturais da sociedade em que estão inseridos. Valorar questões como “anormais", "ilegítimas" ou "desviantes" dependem de algum julgamento moral, e o mapa de significados atuará aí. 


\section{A MORTE DAS MULHERES E DOS HOMENS INFAMES EM ZERO HORA: UMA ANÁLISE DO SILÊNCIO}

Com as relações de forças que operam na construção dos relatos de realidade do jornalismo um pouco mais nítidas, nos habilitamos agora à análise dos casos em si. A intenção, repetimos, é compreender como as mortes de pessoas em situação de rua são retratadas no jornalismo tradicional, tomando por base as matérias publicadas no site do jornal Zero Hora ${ }^{14}$.

\subsection{Primeiro passo metodológico: encontrar as notícias}

De início, a procura aleatória em plataformas de busca ou mesmo no banco de dados online da própria publicação se mostrou um processo infrutífero ${ }^{15}$ - tratamos, afinal, das pequenas notas e dos conteúdos sem maior destaque. Para encontrá-los, foi necessário utilizar outras estratégias. Ademais, procurar apenas o que foi publicado é desconsiderar todas as histórias que, em algum eixo, não cumpriram os critérios de noticiabilidade e sequer se transformaram no "produto final" notícia - e estas, imaginamos, podem interessar mais para a investigação.

Assim, o passo seguinte foi garimpar notícias no jornal impresso "Boca de Rua" sobre acontecimentos violentos que resultaram em mortes de pessoas em situação de rua. Por se tratar de um jornal especializado, produzido exatamente por moradoras e moradores de rua, ali as notícias sobre esta população se encontram em destaque. Em sua edição de número 63, referente aos meses de abril, maio e junho de 2017, o Boca de Rua dedicou amplo espaço a casos de violência. Além da capa e da contracapa, cinco matérias e uma entrevista (com a delegada responsável pela investigação de um dos casos noticiados no jornal) abordaram a temática.

As reportagens contam as histórias de quatro moradoras e moradores de rua assassinados em Porto Alegre com requintes de crueldade: Ana Carmem foi encontrada

\footnotetext{
${ }^{14}$ www.zh.clicrbs.com.br/

${ }^{15}$ Diversas combinações de palavras foram usadas na busca pelas matérias. O buscador de Zero Hora, em todas as vezes, se mostrou bastante ineficaz: ao procurarmos por "morador de rua morto", surgiram notícias de 2008, 2010, 2012 - nenhuma deles fazendo referência a casos de morte de moradores de rua (aliás, sequer fazendo relação com qualquer assunto relacionado a moradores de rua: o primeiro resultado é o caso de morte de um morador de Blumenau (SC) em 2010; o segundo anuncia o lançamento de material inédito, em 2008, do escritor Flávio Moreira; a terceira é uma matéria especial do Diário Gaúcho, jornal popular também do Grupo RBS, donos de Zero Hora, de título "Refugiados do tráfico".
} 
estrangulada dentro de um contêiner de lixo; Jederson Michel foi morto com pancadas de paralelepípedo na cabeça no centro da cidade ${ }^{16}$; Rodrigo Veloso foi espancado por torcedores de um clube de futebol e recebeu golpes com um taco de beisebol - passou cinco dias internado no hospital diagnosticado com traumatismo craniano antes de falecer; Paulo Ricardo foi atingido por diversos tiros na Praça da Matriz - é nessa praça, no centro da cidade, que ficam as sedes dos poderes Executivo, Legislativo e Judiciário, além da Catedral Metropolitana.

A partir das ocorrências publicizadas pelo Boca de Rua, foi possível nortear a busca no site do jornal Zero Hora. O buscador do site, porém, provou-se uma vez mais inútil, o que nos levou a recorrer à plataforma Google para encontrar as notícias. No processo de busca, utilizamos diversas combinações de palavras ou termos, como: "morte morador de rua Porto Alegre Zero Hora"; "assassinato morador de rua Porto Alegre"; e também dados específicos sobre os acontecimentos, "taco beisebol morador de rua Porto Alegre"; ou ainda diretamente com o nome das vítimas, "Jederson Michel morte Zero Hora". Como resultado, três notícias foram encontradas - a exceção foi o caso de Rodrigo, do qual não encontramos nenhum registro. Na busca, observamos que a maior importância dada foi ao caso de Paulo Ricardo: ele aparece como primeiro resultado na maioria das combinações tentadas. A notícia sobre a morte de Ana foi a mais difícil de localizar, sendo necessário que acrescentássemos a palavra “contêiner" no buscador para obtermos sucesso.

A repercussão do assassinato de Paulo na mídia local deve-se em muito ao local e ao horário em que ocorreu o fato (durante o dia); Zero Hora, por exemplo, produziu uma matéria mais extensa sobre o caso. Porém, os outros dois assassinatos, de Ana e de Jederson, ocorridos nos meses de abril e maio, respectivamente, apesar do grau de violência demonstrado pelos agressores, foram reportados em pequenas notas, sem maiores detalhes. O caso de Jederson é curioso também pelo fato de, na mesma semana, outro caso semelhante ter acontecido em Porto Alegre - em consequência, pela falta de aprofundamento e informações nas matérias a respeito, que sequer citam nomes, foi difícil distinguir qual das notas se referia ao assassinato de Jederson. Foi através da rua onde o crime aconteceu que pudemos diferenciar um crime do outro. A respeito da morte de Rodrigo, vítima de brutal violência, nenhuma informação foi encontrada (e nem em outros veículos da mídia local). O jornal Boca de Rua serviu de apoio e contraponto para encontrar informações sobres os casos de violência contra moradoras e 
moradores de rua em Porto Alegre no site de Zero Hora, e sem este passo talvez esta análise sequer seria possível.

\subsection{Segundo passo: uma análise do silêncio}

Para dar início à análise dos acontecimentos noticiados, discorreremos sobre os textos à luz da Análise do Discurso (ORLANDI, 1992; 1999), especialmente atentos aos silêncios e ao não-dito, que têm grande potencial significativo e podem desnudar o mapa de significados teorizado por Hall et al. (1978), tornando visível as ideologias que subjazem as palavras utilizadas nos discursos das matérias do jornal, caracterizando ausências como formas de silenciamento. A política do silêncio (silenciamento) ${ }^{17}$ definida por Orlandi (1992) esconde também a assimetria entre interlocutores, as relações de força (processo) que transformam os textos (produtos finais) no que são, e ela devemos destrinchar.

Todavia, observar o não-dito apresenta alguns desafios: ao passo em que a linguagem disciplina o significar, o ordena e o doméstica, o silêncio é disperso e fugaz, ele "[...] escorre por entre a trama das falas" (ORLANDI, 1992, p.34). É disforme e não é redutível a fórmulas simplificadoras: o silêncio opera, mais que tudo, na ordem do sensível: "Não podemos observálo senão por seus efeitos (retóricos, políticos) e pelos muitos modos de construção da significação.” (ORLANDI, 1992, p.48).

No âmbito analítico-processual, dois passos foram tomados: primeiro, a definição das posições de sujeito (quem produz discursos e quem tem discursos produzidos sobre si); e, segundo, a delimitação de formações discursivas, que são, em suma, sentidos centrais que configuram um discurso - delas poderemos inferir sentidos não perceptíveis ao primeiro olhar desatento. Isso significa ir ao texto e voltar à análise para depois mergulhar uma vez mais nos relatos e retornar de novo: a Análise do Discurso exige um contato íntimo entre objeto empírico e teoria (BENETTI, 2008). Com tais procedimentos, efetuar-se-á a "de-superficialização" das matérias: uma análise da materialidade linguística (o texto em si), como é dito, por quem, em que circunstância, desvelando, pelo não-dito, que o dito poderia o ser de outra forma (ORLANDI, 1999). Os movimentos nos conduzirão, portanto, da superfície linguística (texto)

\footnotetext{
${ }^{17}$ Orlandi (1992) difere os tipos de silêncio: o silêncio fundador existe nas palavras, significa o não-dito; e a política do silêncio impõe o silenciamento, reforçando que para dizer é necessário não-dizer: uma palavra "apaga" as outras. Dessa forma, a autora vê ambiguidade no silêncio, um polo negativo e outro positivo, servindo tanto a uma retórica da dominação (opressor) quanto a uma retórica da resistência (oprimido).
} 
ao objeto discursivo e, enfim, ao desnudamento do processo discursivo, onde descansa a ideologia, que, por sua vez, opera os mapas de significação.

\subsection{Três mortes noticiadas e um silêncio que grita}

Um silêncio nos pareceu mais gritante: a ausência de notícias sobre o assassinato de Rodrigo - um cruel espancamento coletivo - simboliza o desinteresse do jornalismo tradicional em relação àqueles que estão em situação de vulnerabilidade social e sofrem as consequências do desamparo social absoluto cotidianamente. A população de rua parece não nos sensibilizar sequer na morte, em que pese a nossa insensibilidade também em relação aos vivos. $O$ fato deste acontecimento não ter sido noticiado sugere que a estratégia por nós adotada nesta pesquisa, a de buscar relatos em outras fontes de informação (no caso, o jornal Boca de Rua), foi fundamental, pois ele serviu de fato como "informante": o esquecimento se impõe não apenas na palavra não escrita, mas também, e talvez de maneira ainda mais significativa, na inexistência da pauta em si. Caso procurássemos apenas os casos noticiados, escapariam aos olhos todas essas notícias que nunca vieram a ser.

Abaixo, construímos um quadro sinalizando os casos analisados em Zero Hora. Nele, apresentamos as manchetes e, em seguida ao quadro, abaixo, os subtítulos e os primeiros parágrafos das matérias.

Quadro 1

\begin{tabular}{|c|c|c|}
\hline Caso & Data da publicacão & Manchete \\
\hline $\begin{array}{c}\text { 1. Paulo Ricardo Camargo } \\
\text { de Oliveira }\end{array}$ & $20 / 03 / 2017$ & $\begin{array}{c}\text { Morador de rua é } \\
\text { assassinado na Praça da } \\
\text { Matriz, no centro de Porto } \\
\text { Alegre }\end{array}$ \\
\hline 2. Ana Carmem & $22 / 04 / 2017$ & $\begin{array}{c}\text { Corpo é encontrado dentro } \\
\text { de contêiner no centro da } \\
\text { Capital }\end{array}$ \\
\hline 3. Jederson Michel & $09 / 05 / 2017$ & $\begin{array}{c}\text { Homem é morto a pedrada } \\
\text { no centro de Porto Alegre }\end{array}$ \\
\hline Rodrigo Veloso & - & - \\
\hline
\end{tabular}

Fonte: Elaborado pelo autor.

Seguem os subtítulos (em itálico) e os primeiros parágrafos das matérias das publicações em Zero Hora. 
1) “Crime ocorreu em frente à Catedral Metropolitana, a poucos metros do Palácio Piratini, do Palácio da Justiça e da Assembleia Legislativa. Diante da Catedral Metropolitana de Porto Alegre, duas idosas aguardavam a missa das 18h30min sentadas em um banco na Praça da Matriz. As conversas aleatórias foram interrompidas por estampidos de cinco tiros endereçados a um morador de rua. Paulo Ricardo Camargo de Oliveira, 36 anos, foi atingido no peito e morreu no local, a 1 metro da lona onde se abrigava. A execução à luz do dia ocorreu às 17h15min na frente da Assembleia Legislativa - onde pelo menos três eventos aconteciam simultaneamente - do Palácio Piratini e do Palácio da Justiça. Flagrada também por um representante comercial e um casal que contemplava o entardecer tomando chimarrão, a ação aconteceu sem a menor discrição."

2) "Segundo a polícia, corpo de mulher de 28 anos apresenta sinais de enforcamento. Perícia será feita para confirmar causa da morte. O corpo de uma mulher foi encontrado dentro de um contêiner na Avenida Borges de Medeiros, no centro de Porto Alegre, no final da manhã deste sábado. A vítima foi identificada como Ana Carmen dos Santos, 28 anos. As informações são da Rádio Gaúcha. De acordo com o delegado João César Nazário, o corpo apresentava sinais de enforcamento, mas a perícia ainda vai confirmar a causa da morte. A polícia suspeita que o crime tenha ligação com o tráfico de drogas. Inicialmente, a Brigada Militar havia informado que a vítima era um homem. A informação foi corrigida pela Polícia Civil."

3) "Vítima foi atingida por pelo menos um golpe na cabeça. Um homem foi morto a pedrada, na madrugada desta terça-feira (9), no centro de Porto Alegre. Segundo informações da BM, a vítima teria sido atingida por pelo menos um golpe com um paralelepípedo na cabeça, na Rua Otávio Rocha, em frente ao número 26 e morreu em via pública. O crime ocorreu por volta das 4h30min. Ainda de acordo com a polícia, o homem morto seria um morador de rua. A identificação da vítima ainda não foi confirmada. A motivação do crime está sendo investigada pela Polícia Civil. Até o momento ninguém foi preso.”

Os casos 2 e 3 são marcados pela aparente linguagem objetiva e imparcial do narrador e denotam frieza. São notas curtas, meros relatos de que algo aconteceu. O discurso direto, sem rodeios literários, funciona apenas como registro da morte de outra mulher (identificada) e outro homem (sem nome). Não possuem "resto do texto": agregamos os parágrafos que compõem as notícias, que se resumem a estes relatos reduzidos, nos quais as únicas fontes de informação são policiais. Tudo que é dito, portanto, vem destes "informantes oficiais". As posições de sujeito são reservadas às autoridades; às vítimas, restam as suspeitas: Ana é 
associada ao tráfico de drogas; Jederson "teria sido" atingido por golpes de paralelepípedo e é logo definido como "morador de rua".

A perspectiva do não-dito, na Análise do Discurso, refere-se a escolha e o uso de determinadas palavras que "apagam" todas outras características possíveis para descrever ambos: o jornal Boca de Rua destaca que Ana era estudante da Escola Porto Alegre e sofria de esquizofrenia. Estas informações demonstram a possível complexificação da situação da história vida desta pessoa e a tragédia que levou à sua morte. Contudo, o faro jornalístico parece falhar nestas situações: quem produziu os textos tinha poucas informações sobre os casos (como se observa na narrativa, a única fonte ouvida foi a polícia). Assim, esses depoimentos foram usados como definidores primários (e únicos); em relação ao texto jornalístico construído a partir deles, o mapa de atuação (significação) dos jornalistas foi julgado suficiente, uma vez que seguiu as regras exigidas por seus pares e superiores, a da "objetividade" jornalística. Neste cenário, o silêncio sobre a morte de quem jamais fora ouvido quando vivo não surpreende em nada. "[...] [O] sentido é sempre produzido de um lugar, a partir de uma posição de sujeito - ao dizer, ele estará, necessariamente, não dizendo 'outros' sentidos. Dizer e silenciar andam juntos" (ORLANDI, 1992, p.55).

A notícia 1, do caso de Paulo, é um pouco mais elaborada. Entretanto, melhor seria nomeá-la "o caso da Praça da Matriz”, já que Paulo ter sido alvejado por tiros parece ter perturbado os usuários de classe média do local: "As conversas aleatórias foram interrompidas", "a execução à luz do dia ocorreu [...] na frente da Assembleia Legislativa onde pelo menos três eventos aconteciam simultaneamente" e "flagrada também por um representante comercial e um casal que contemplava o entardecer tomando chimarrão, a ação aconteceu sem a menor discrição" são três frases apresentadas logo no início do texto. Ao longo da matéria, as principais posições de sujeito são usuários da praça: além da rotina quebrada, relata-se a sensação de medo. Tais jogos de palavras levam a crer que, ocorresse o crime com discrição - como, aliás, acontecem (não com discrição, mas bem longe das páginas dos jornais) nas periferias do Brasil afora ${ }^{18}$-, não causariam maiores problematizações, pois não teriam visibilidade alguma. Percebe-se um discurso higienista que coloca na vítima a culpa pela sua tragédia - não houvesse morador de rua na praça, não haveriam tiros: o casal poderia

\footnotetext{
18“"Estudo realizado pelo Ipea e pelo Fórum Brasileiro de Segurança Pública mostra que jovens e negros são as principais vítimas de violência no país”. Disponível em: http://www.ipea.gov.br/portal/index.php?option=com_content\&view=article\&id=30253. Acesso em: 27/06/2017.
} 
contemplar o entardecer e tomar seu chimarrão em paz; os eventos da Assembleia Legislativa não seriam perturbados; as conversas aleatórias seguiriam seus percursos irrisórios.

A relação com o tráfico é de novo aventada em relação a Paulo, e uma vez mais notase a presença dos detentores de poder na posição de definidores primários (HALL et al., 1978): policiais militares são as autoridades ouvidas, aqueles que poderão revelar ao jornalista, e em consequência aos leitores, o que de fato ocorreu. Os usuários da praça têm impressões; as autoridades, a verdade.

Cabe ressaltar que em nenhum dos casos foi encontrada matéria subsequente, abordando o desandar das investigações. Logo, aquilo que nesse momento é apenas suposto, assim permanece, com o estatuto de provável. O silêncio aqui não cria esquecimento: pelo contrário, significa uma memória que perdurará, já que inconteste. Como afirmam Bird e Darndenne (1999, p.267) a partir de Graber (1984), “os leitores raramente se recordam de detalhes de 'estórias' sobre o crime, e não 'utilizam' a informação nas suas vidas diárias (GRABER, 1984). Em vez disso, as 'estórias' tornam-se parte de uma 'estória' ou mito mais amplo acerca do crime e valores". Independentes de se mostrarem fatos verdadeiros, as acusações feitas a Paulo e a Ana são construídas a partir dos mapas de significação e terão, daí em diante, desenho de verdade, reforçando concepções já instituídas e internalizadas sobre moradores de rua estarem envolvidos com drogas.

Ao longo da matéria que relata o caso da Praça da Matriz, há, a partir do sétimo parágrafo, a descrição sobre o perfil de Paulo. O destaque é dado à profissão: "era desenhista". No relato do jornal, aparecem os seguintes adjetivos à personagem: "gentil e cortês" (por "uma moradora da região"), ao que os jornalistas acrescentam que "inclusive, abria a porta do carro para as pessoas"; um jovem comenta que Paulo "entendia sobre tudo", "era um grande desenhista", mas “muito brigão"; e "moradores de rua da região" também contam que "Oliveira trabalhava como cuidador de carros e vendedor de jornal", e aqui os jornalistas acrescentam a informação de que "há três anos vivendo na praça, [Paulo] era considerado o mais inteligente do grupo que se abriga no entorno".

Há, portanto, uma tentativa de "humanizar" a personagem a partir daquilo que é dito no discurso do jornal. Características além da situação do "morar na rua” são apontadas e libertam, em alguma medida, Paulo deste estigma. Contudo, o não-dito transmite sentidos outros: as fontes de informação dos traços do perfil de Paulo são "ninguém": tudo o que sabemos sobre o “jovem”, personagem que parece conhecer a vítima com maior grau de profundidade, é que provavelmente tem entre 15 e 30 anos e é do gênero masculino. Das seis vozes que ganham 
espaço de fala, apenas uma é nomeada: o delegado Cassiano Cabral. A voz oficial da polícia ganha autoridade sobre as demais - exatamente a voz que trata o caso "[...] como uma execução. A principal linha de investigação é acerto de contas em razão do tráfico de drogas, já que a vítima tinha passagem pela polícia por posse de entorpecentes.”

\section{CONSIDERAÇÕES FINAIS}

Nossa análise considera que os discursos - e inclusive o nosso aqui - estão subordinados a mapas de significação socialmente compartilhados (HALL et al., 1978), cuja ideologia “consensual” molda as ações dos sujeitos na vida cotidiana - inclua-se aí as práticas dos jornalistas e as escolhas dos critérios de noticiabilidade no processo de construção da notícia. Nossa abordagem considerou três os patamares dos critérios de noticiabilidade: 1) aqueles intrínsecos, ou seja, os valores-notícia em si (que podem ser morte, notoriedade, proximidade, etc., variando de acordo com autoras e autores); 2) os extrínsecos (questões organizacionais, burocráticas, constrangimentos variados, a corrida contra o tempo - é impensável que um jornal termine o dia sem notícias para noticiar, independente se houve fatos noticiáveis ou não); e 3) os mapas de significado, noções de mundo socialmente compartilhadas que afetam tanto a produção de notícias quanto a sua recepção. Defendemos que há uma subordinação do primeiro ao segundo e deste ao terceiro, sem negar, contudo, a interdependência entre todos, que se retroalimentam.

Ao tratarem de rupturas, do inesperado, daquilo tido por "anormal" ou "novo", as notícias têm a função de tornar dados desconhecidos em inteligíveis: "Trazer os eventos para o domínio dos significados representa, em essência, referir o incomum e o inesperado nos 'mapas de significado' que já formam a base de nosso conhecimento cultural, no qual a realidade social já está 'mapeada"” (HALL et al., 1978, p.54). O desconhecido, portanto, que por meio do jornalismo transita ao campo do que nos é familiar, realiza esse movimento de acordo com um mapa já desenhado; ao permitir que as vozes poderosas signifiquem majoritariamente os acontecimentos sociais, o jornalismo favorece uma leitura única da realidade, silenciando todas as outras verdades possíveis.

Assim, a perspectiva de Peucer (2004) continua atual, três séculos mais tarde: importa ao jornalismo - em consequência de importar à sociedade - a morte e a vida dos príncipes e dos varões ilustres. Às mulheres e aos homens infames, resta o silêncio e o esquecimento ou, se tanto, uma pequena nota perdida na nuvem da internet. Diferente do que defende Traquina 
(2013), não basta morrer para ganhar as páginas do jornal: a algumas pessoas é necessário uma violência brutal, como ser enforcada e jogada dentro de um contêiner de lixo, ser atingido na cabeça por golpes de paralelepípedo ou ser alvejado com cinco tiros à queima-roupa em plena luz do dia na Praça dos Poderes para que suas mortes sejam consideradas dignas de registro e memória. A população de rua tem negada a sua humanidade e existência mesmo ao fim delas. Nesta visão estreita do jornalismo tradicional, com frequência ouve-se referência a pessoas em situação de rua como invisíveis. Ora, o fato de não os vermos não faz deles invisíveis: faz de nós, cegos - e urge, assim, um discurso jornalístico humanizado, que trate como sujeitos aqueles que vivem em situação de exclusão social ${ }^{19}$.

\section{REFERÊNCIAS}

BAUMAN, Zygmunt. O mal-estar da pós-modernidade. Rio de Janeiro: Jorge Zahar Ed., 1998.

BENETTI, Marcia. Análise do Discurso em jornalismo: estudo de vozes e sentidos. LAGO, Cláudia; BENETTI, Marcia. (Orgs.). Metodologia de pesquisa em jornalismo. Petrópolis, RJ: Vozes, 2008.

BERGER, Peter L.; LUCKMANN, Thomas. A construção social da realidade: tratado de sociologia do conhecimento. Petrópolis: Vozes, 2003.

BIRD, S. E.; DARNDENNE, R. W. Mito, registro e 'estórias': explorando as qualidades narrativas das notícias. In: TRAQUINA, N. (Org.). Jornalismo: questões, teorias e "estórias". Lisboa: Veg, 1999.

FONSECA, Virginia Pradelina da Silveira. Indústria de notícias: capitalismo e novas tecnologias no jornalismo contemporâneo. Porto Alegre: Editora da UFRGS, 2008.

HALL, Stuart; CRITCHER, Chas; JEFFERSON, Tony; CLARKE, John; ROBERTS, Brian. Policing the crisis: mugging, the State, and Law and Order. The Macmillan Press LTD: London, 1978.

MEDINA, Cremilda. Entrevista: o diálogo possível. São Paulo: Editora Ática, 2008.

\footnotetext{
${ }^{19}$ Vale acrescentar, ao fim, a interessante iniciativa da ONG feminista Olga, que produziu um "minimanual" sobre como praticar um jornalismo humanizado. Disponível em: https://thinkolga.com/2018/01/31/minimanual-dejornalismo-humanizado/. Acesso em: 15/01/2018.
} 
- INOVAÇÃo

ORLANDI, Eni Puccinelli. As formas do silêncio no movimento dos sentidos. Campinas: Editora da UNICAMP, 1992.

Análise de discurso: princípios e procedimentos. Campinas: Pontes, 1999.

PEUCER, Tobias. Os relatos jornalísticos. Estudos em jornalismo e mídia, Vol. 1, ํㅡㄴ 2, ㄴo semestre de 2004.

PONTE, Cristina. Leitura das notícias: contributos para uma análise do discurso jornalístico. Lisboa: Livros Horizonte, 2004.

SILVA, Gislene. Para pensar critérios de noticiabilidade. Estudos em jornalismo e mídia, Vol. 2, ํㅡㄴ 1, 1ํ semestre de 2005.

TRAQUINA, Nelson. Teorias do Jornalismo: porque as notícias são como são. Vol.1. Florianópolis: Insular, 2004.

Teorias do jornalismo: a tribo jornalística, uma comunidade interpretativa transnacional. Vol. 2. Florianópolis: Insular, 2013. 


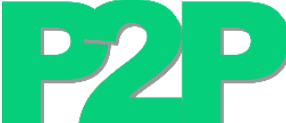

? INOVAÇão

69

P2P \& INOVAÇÃO, Rio de Janeiro, v. 4 n. 2, p.53-69, Mar./ Ago. 2018. 